\title{
Combating overreporting of deductions in tax returns: prefilling and restricting the deductibility of expenditures
}

\section{Martin Fochmann ${ }^{1,2}$ (D) Frank Hechtner ${ }^{3} \cdot$ Tobias Kölle $^{4} \cdot$ Michael Overesch $^{4}$}

Accepted: 7 December 2020 / Published online: 30 January 2021

(C) The Author(s) 2021

\begin{abstract}
We experimentally analyze three anti-tax-evasion mechanisms: (1) prefilling of deductions in tax returns, (2) restricting tax evasion opportunities by either disallowing or (3) limiting the deductibility of expenditures. We find that prefilling compared to blank forms reduces tax evasion. Cutting the number of tax evasion opportunities by disallowing the deductibility of expenditure items is an ineffective mechanism to combat tax evasion as individuals shift their tax evasion activities from the disallowed item to other non-restricted items. In contrast, our results suggest that just limiting the deductibility of expenditures avoids this evasion-shift-effect.
\end{abstract}

Keywords Tax compliance - Tax evasion · Deductions · Prefilled tax returns · Behavioral economics

JEL Classification C91 · D90 $\cdot$ H26 $\cdot$ K42

Supplementary Information The online version of this article (https://doi.org/10.1007/s11573-02001024-7) contains supplementary material, which is available to authorized users.

Martin Fochmann

martin.fochmann@fu-berlin.de; fochmann@wiso.uni-koeln.de

Frank Hechtner

frank.hechtner@fau.de

Tobias Kölle

tobias.koelle@wiso.uni-koeln.de

Michael Overesch

overesch@wiso.uni-koeln.de

1 Freie Universität Berlin, Thielallee 73, 14195 Berlin, Germany

2 University of Cologne, Albertus-Magnus-Platz, 50923 Cologne, Germany

3 Friedrich-Alexander-Universität Erlangen-Nürnberg, Lange Gasse 20, 90403 Nuremberg, Germany

4 Business School, University of Cologne, Albertus-Magnus-Place, 50923 Köln, Germany 


\section{Introduction}

Tax evasion continues to be a serious problem in society and rising media coverage of evasion scandals heightens the urgency to act. Initiated by the seminal papers of Becker (1968), Allingham and Sandmo (1972) and Yitzhaki (1974), a variety of papers have studied tax evasion and dishonest behavior. ${ }^{1}$ Researchers focused primarily on tax evasion of income/earnings although overreporting of deductions might be the only possibility to evade taxes for many people (such as typical wage earners) due to third party income reporting. Consequently, deductions are rather underrepresented in tax compliance literature in view of their importance. In our study, we therefore focus on deductions, in particular on how individuals report expenditures in a tax return. We examine the influence of three mechanisms applied to combat tax evasion behavior: (1) prefilling of deductions in tax returns, (2) restricting tax evasion opportunities by either disallowing the deductibility of expenditures or (3) limiting the deductibility of expenditures. For our purpose, we run an experiment in a controlled environment and analyze expenditure items that are substantial in real life.

Nowadays, taxpayers often start their tax declarations with tax returns in which income and/or deduction items are already prefilled. On the one hand, automatic data exchanges between the tax authority and employers, social insurance agencies and banks allow tax returns to be prefilled (third party reporting). On the other hand, electronic tax declaration programs (e-filing services) usually carry over the previous year's values to the subsequent year (which assists taxpayers at least as an orientation aid) and therefore prefill the current tax return with last year's numbers (e.g., deductions, expenditures, salary, tax credits). A prefilled tax return supports taxpayers to file a legally accurate tax return (Goolsbee 2006; Klun 2009; Evans and Tran-Nam 2010; OECD 2017). However, literature provides only little and mixed evidence regarding the effects of prefilling on tax compliance (see Sect. 2.1). Prefilling of deductions in tax returns is likely to affect the monetary costs associated with tax evasion especially due to a higher (perceived) detection probability of tax fraud in case of third party reporting. As the tax compliance literature already provides robust results that a higher detection probability has a positive impact on tax compliance (Torgler 2002), we focus on the non-monetary and more psychological consequences of prefilling in our study. We therefore ensure that all monetary aspects such as tax rate, detection probability, and penalties are kept constant. Finally, our data shows that the prefilling of deductions compared to blank forms reduces tax evasion significantly. This highlights the importance of the non-monetary consequences of prefilled tax returns and provides evidence that prefilling of deductions is an effective mechanism to enhance tax compliance.

To combat tax evasion, policy makers frequently restrict tax evasion opportunities-either by disallowing or limiting the deductibility of expenditures. Disallowing the deductibility cuts the number of opportunities to evade taxes. Many

\footnotetext{
${ }^{1}$ See Andreoni et al. (1998), Torgler (2002), Hofmann et al. (2008), Alm (2012), Slemrod (2016) and Alm (2019) for excellent literature reviews.
} 
countries-like the US, UK, France and Germany-have rather strict rules and consequently disallow the deductibility of, for example, expenditures regarding office space at home, work clothes that are also usable for private purposes, high priced gifts for customers and business clients, and fines. Instead of disallowing the deductibility completely, deductibility of expenditures is sometimes only limited to a certain amount. German tax law for example limits the deductibility of travel expenses, social insurance expenses, food expenses of employees in case of external activities, childcare expenses, and expenses for household-related services. Remarkably, the effects of restricting the deductibility of expenditures on individual tax evasion behavior is unexplored in the literature. However, some recent research in a related context indicates that taxpayers might shift their evasion behavior to compensate for such limitations (Adhikari et al. 2016; Asatryan and Peichl 2017; Carrillo et al. 2017; Slemrod et al. 2017; Vossler and Gilpatric 2018).

Our study provides evidence to the literature that cutting the number of tax evasion opportunities by disallowing the deductibility of expenditure items is an ineffective mechanism to combat tax evasion. Our data shows that individuals shift their tax evasion activities from the disallowed item to other non-restricted items (evasion-shift-effect). In contrast, our results suggest that just limiting the deductibility of expenditures avoids this evasion-shift-effect. A limited deductibility seems to be an effective mechanism to combat tax evasion.

The remainder of this paper is structured as follows. We briefly discuss the related literature in Sect. 2 and develop our hypotheses in Sect. 3. In Sect. 4 we describe the experimental design and results are presented in Sect. 5. Section 6 concludes.

\section{Related literature}

\subsection{Effects of prefilling on tax compliance}

Our research question of how prefilling of expenditure items in a tax return influences tax compliance behavior is largely unexplored. Although some papers study prefilling (especially third-party reporting), they mainly focus on the prefilling of income items and show mixed results. A positive effect of third-party reporting is found by Kleven et al. (2011), who analyze data from a tax enforcement experiment in Denmark. Their focus is not on prefilled tax returns directly, but third-party reported data is prefilled by the tax authority in the tax returns. The authors find that tax evasion is very low for income subject to third-party reporting and thus already prefilled in tax returns; however, they find that tax evasion is substantial for selfreported (i.e., not prefilled) income. Fochmann et al. (2018) show in a laboratory experiment that a correct prefilling of income items enhances tax compliance compared to a setting without prefilling. In a neutral dice rolling experiment without tax framing and without audit or punishment, Duncan and Li (2018) find that confirmation reports (comparable to correct prefilling) have a positive effect on compliance behavior. However, dishonest behavior cannot be analyzed on an individual level.

In contrast, some studies find no or even a negative effect of prefilling on compliance. Kotakorpi and Laamanen (2016) use data from a natural experiment in Finland 
and examine tax reporting behavior when taxpayers receive prefilled tax returns. The authors observe that prefilling increases the number of deductions claimed but not the number of income items reported. Rather, the authors find a significant reduction in the number of reported items that were not prefilled. More importantly, on an aggregated level, they do not find that prefilled tax returns influence total taxable income or taxes paid.

Fonseca and Grimshaw (2017) use an online experiment to study the effects of behavioral nudges on prefilled tax returns. Without nudges, they find that correct prefilling does not increase overall compliance, but that incorrect prefilling reduces compliance. However, this result is mainly driven by the fact that over-compliant participants (i.e., individuals who report a higher taxable income than they actually have and thus pay more taxes), are categorized as non-compliant subjects. In case the tax return is incorrectly prefilled with an income too low (i.e., the prefilled income is lower than the randomly assigned income), they observe that the introduction of a checkbox as a physical barrier to change prefilled fields further decreased compliance, but combining the checkbox with a fictitious norm message does not influence the overall compliance level.

Bruner et al. (2015) investigate reporting behavior for partly prefilled tax returns and focus on different opportunities for underreporting deductions. In a complex setting, they vary the audit probability, the presence of itemized deductions, and the uncertainty about the correct values. They find that correct as well as incorrect prefilling reduces overall compliance. Gillitzer and Skov (2018) use data from the Danish tax authority and examine the case of prefilled deductions. Contrary to their expectations, they find that the number of tax deductions claimed doubles and that the total value of deductions increases if tax-deductible charitable contributions are already prefilled in the tax return. The authors suggest that taxpayers neglect to claim their tax-deductible charitable contributions if they are not already prefilled.

Our study substantially differs from previous studies in several dimensions. We use a parsimonious laboratory experiment that enables us to focus on the influence of prefilled expenditure items on compliance behavior in a controlled environment. A laboratory experiment allows us to analyze the level of tax compliance in more detail and excludes that the analysis is biased by undeliberate tax evasion behavior. Our experimental design differs in many ways from that of Bruner et al. (2015), Fonseca and Grimshaw (2017) and Fochmann et al. (2018). We focus on prefilled expenditure items, not mixing it with prefilled income items, in order to clearly focus on the effects for deductions, as previous studies show that reporting behavior may differ for income and deductions (Fochmann and Wolf 2019). We use a real effort game, so that participants have to earn their income, instead of using a windfall gain. We exclude that uncertainty about the audit probability (as in Fonseca and Grimshaw 2017) might influence our results.

Our design controls for several potential explanations discussed by the studies mentioned above. Kleven et al. (2011), Gillitzer and Skov (2018) and Kotakorpi and Laamanen (2016) suggest that compliance is much higher for third-party reported (i.e., prefilled) items because the possibility of evading taxes is limited. We exclude this explanation with our experimental design, as our treatments offer the same opportunities for tax evasion in the cases of both prefilled and blank tax forms. 
Kotakorpi and Laamanen (2016) further discuss complexity effects as a possible explanation for changes in reporting behavior. We control for complexity by keeping the compliance decision in our experiment very simple. Participants have full information, there are no computation needs and complexity does not differ between treatments.

\subsection{Disallowing and limiting the deductibility of expenditures}

Disallowing or limiting the deductibility of expenditures (e.g., capping the total amount of expenditures) are frequently discussed topics in the literature. For example, Feldstein (2015) advocates for these mechanisms to tackle rapidly increasing national debt for the United States by restricting the amount of taxes refunded. In 2012, the UK already implemented a single cap on all personal deductions. Expenditures can only be deducted up to an amount of $\$ 50,000$ or-if greater-25\% of income. This cap stimulated debates on potentially negative effects on for instance charitable donations (Smith 2012). This is why Schizer (2015) criticizes the idea of a one-size-fits-all cap and suggests to apply different expenditure-specific caps. However, Lowry (2014) estimates that several combinations of deduction limits may shift taxpayers to claim standard deduction instead of itemizing. As a consequence, the expected growth in tax revenues from limiting deductions would be partially offset. All in all, there are multiple dimensions to be considered when limiting expenditures. For example, its effect on income distribution, labor and savings decisions, or planning and administrative costs. However, the effect of limiting expenditures on tax evasion keeps unexplored thus far. It is unclear whether limiting deductions indeed reduces total overdeductions or taxpayers adjust their behavior for example by shifting overdeductions to other (non-restricted) items.

There is some research suggesting that taxpayers might change their behavior to avoid such restrictions. For example, in Chile diesel taxes paid can be fully used as a credit against VAT. However, this is only allowed if diesel is used in industrial activities. Otherwise, if diesel is for example used in freight or public transportation, this rule gets restricted as only a fraction of diesel taxes paid can be claimed as a tax credit for VAT. Agostini and Martínez (2014) investigated this regulation and show that firms actively manipulate the classification to avoid this restriction. Carrillo et al. (2017) suggest that taxpayers facing third-party reporting of one income item (i.e., tax evasion opportunity gets limited) make offsetting adjustments on other items. In particular, after a policy intervention, Ecuadorian firms increased reported revenue but at the same time also increased reported costs by 96 cents per dollar of revenue adjustment. Such an offsetting-effect is also found by Slemrod et al. (2017) who investigate the response of US sole proprietorships to Form 1099-K that provides the IRS with third-party information about electronic sales. Even though there is, as expected, an increase in reported receipts, taxpayers largely offset this increase "with increased reported expenses, which do not face information reporting, diminishing the impact on reported net taxable income" (p. 1). This finding is supported by Adhikari et al. (2016) who show for the taxicab industry that the increase in receipts due to third-party income reporting of Form 1099-K is offset by an increase 
in expenses. More evidence is also provided by Asatryan and Peichl (2017) who observe that Armenian firms respond to additional reported income raised by audits with a similar increase in deductions. Vossler and Gilpatric (2018) confirm the offsetting-effect in a controlled laboratory experiment. They show that revealing the item that is targeted in an audit leads individuals to report more truthfully on this item. However, at the same time they evade more on other items.

All in all, these studies do not focus on our research question directly, as the aim of our paper is to study how restricting the deductibility of expenditures impacts tax evasion behavior. However, they do indicate that limiting evasion opportunities might lead taxpayers to adjust their tax evasion behavior to compensate for such restrictions.

\section{Hypotheses}

Tax compliance literature started to focus on how monetary factors such as tax rate, audit probability and fines determine tax compliance behavior (Becker 1968; Allingham and Sandmo 1972; Srinivasan 1973; Yitzhaki 1974). This literature provides robust evidence that a higher audit/detection probability as well as a higher fine reduces tax evasion (Spicer and Thomas 1982; Alm et al. 1995; Maciejovsky et al. 2001; Torgler 2003; Cummings et al. 2009; Fortin et al. 2007; Gërxhani and Schram 2006). More recently, literature studies how non-monetary and more psychological factors such as social norms, tax morale, fairness concerns, trust and services provided by the tax authority influence tax compliance (Andreoni et al. 1998; Torgler 2002; Hofmann et al. 2008; Alm 2012, 2019). ${ }^{2}$ From these findings, new frameworks such as the slippery slope framework (Kirchler et al. 2008) and new paradigms such as the service and trust paradigm (Alm 2012, 2019) have evolved. This literature suggests that a higher trust in the tax authority (e.g., by enhancing procedural fairness) and a higher service quality of the tax authority increases tax compliance (Alm 2019; Hofmann et al. 2008; Kirchler et al. 2008).

\subsection{Prefilling of deductions}

One promising mechanism to enhance tax compliance is prefilling of deductions in tax returns. We argue that prefilling might signal advanced information of the tax authority about the expenditures of an individual. Moreover, individuals might believe that deviating from the prefilled values will increase the probability that the tax authority audits the tax return. Consequently, prefilling of an item should lead to a higher subjective detection probability and might therefore lower tax evasion.

Moreover, prefilling might also increase the non-monetary costs of tax evasion. ${ }^{3}$ First, prefilling of tax returns might lead to default effects (Johnson and Goldstein

\footnotetext{
${ }^{2}$ Even the theoretical tax compliance literature has already started to consider non-monetary factors to explain/predict tax compliance behavior (e.g., Fortin et al. 2007; Gordon 1989; Kim 2003; Myles and Naylor 1996; Traxler 2010; Prinz et al. 2014).

3 See Fochmann et al. (2018) for a more detailed discussion.
} 
2003; Mazar and Hawkins 2015) or anchoring effects (Tversky and Kahneman 1974; Epley and Gilovich 2001; Strack and Mussweiler 1997; Chapman and Johnson 1999) that bias individuals toward the prefilled values of the tax return. Correctly prefilled tax returns would then nudge individuals toward more tax compliance. Second, in case of correct prefilling, we argue that the act of replacing correct values with incorrect numbers in order to evade taxes increases the moral costs associated with tax evasion. Third, due to a better service, individuals might perceive a higher procedural fairness when the tax authority prefills tax returns compared to blank forms. Literature provides conclusive evidence that higher procedural fairness is associated with higher tax compliance which can also be operationalized by an increase in the non-monetary costs of tax evasion (Alm 2019; Hofmann et al. 2008; Kirchler et al. 2008). All three effects might consequently result in a lower tax evasion level.

In line with the results of Fochmann et al. (2018) who analyzed the prefilling of income items and observed a lower tax evasion level with correctly prefilled items than with blank items, we formulate our first hypothesis as follows:

Hypothesis 1 Prefilling of deductions in tax returns reduces the tax evasion level.

\subsection{Restricting the deductibility of expenditures}

\subsubsection{Disallowing the deductibility of expenditures}

Another mechanism to enhance tax compliance might be disallowing the deduction of specific expenditure items. Under the assumption, that taxpayers refrain from shifting tax evasion activities to other non-restricted items, the overall tax evasion level will decrease. We formulate our Hypothesis 2a therefore as follows:

Hypothesis 2a Disallowing the deductibility of an expenditure item does not affect the tax evasion level of other non-restricted items and reduces the overall tax evasion level.

However, if taxpayers shift their tax evasion activities to other non-restricted expenditure items, the tax evasion level for those items will increase. This would be in line with the finding that taxpayers increase claimed deductions to offset an increase in reported income due to third-party reporting or audits (Adhikari et al. 2016; Asatryan and Peichl 2017; Carrillo et al. 2017; Slemrod et al. 2017; Vossler and Gilpatric 2018). Moreover, it might be that individuals feel unfairly treated when the deductibility of an expenditure item is restricted or even completely disallowed. Consequently, perceived procedural fairness might be reduced (reactance) which results in more tax evasion (Hofmann et al. 2008; Kirchler et al. 2008). As the shift in tax evasion to non-restricted items might undercompensate, compensate, or even overcompensate (due to reactance) the positive effect of a disallowance on 
tax evasion, we refrain from hypothesizing the influence that this mechanism has on overall tax evasion. We therefore formulate Hypothesis $2 b$ as follows:

Hypothesis $2 b$ Disallowing the deductibility of an expenditure item increases the tax evasion level of other non-restricted items.

\subsubsection{Limiting the deductibility of expenditures}

A third mechanism to combat tax evasion might be to limit the deductibility of expenditures. Thus, the deductibility of expenditures is neither completely allowed nor disallowed, but limited. Again, the effect of such a restriction on the overall tax evasion level depends on whether taxpayers shift tax evasion activities to other nonrestricted items or not. Hence, we formulate the following two hypotheses:

Hypothesis 3a Limiting the deductibility of an expenditure item does not affect the tax evasion level of other non-restricted items and reduces the overall tax evasion level.

Hypothesis $3 b$ Limiting the deductibility of an expenditure item increases the tax evasion level of other non-restricted items.

\section{Experimental design and treatments}

\subsection{Experimental design of the three main parts}

We conduct a laboratory experiment consisting of the following three parts: (1) real effort task, (2) donation and (3) tax return (see Fig. 1). The instructions for each part are provided to the participants at the beginning of the corresponding part and are shown in our online Appendix A1.

In the first part of the experiment (real effort task), participants generate their (pre-tax) income by solving math puzzle tasks introduced by Mazar et al. (2008). Participants see matrices with twelve numbers (each with two decimal places) on their screen and have to select the two numbers that add up to ten (e.g., $6.61+3.39=10$ ). The math puzzle is a search task in which participants have to put in some effort to correctly solve the puzzles to earn money. In each matrix, there are only two numbers that add up to ten. Participants play four payoff-relevant rounds of the math puzzle task and in the beginning one testing-round, each lasting three minutes, with a one-minute break between the rounds. In each round, they can solve a maximum of 20 puzzles. For every correctly solved math puzzle, a participant earns a pre-tax income of 93 Eurocent (0 Eurocent otherwise). After each round of the 


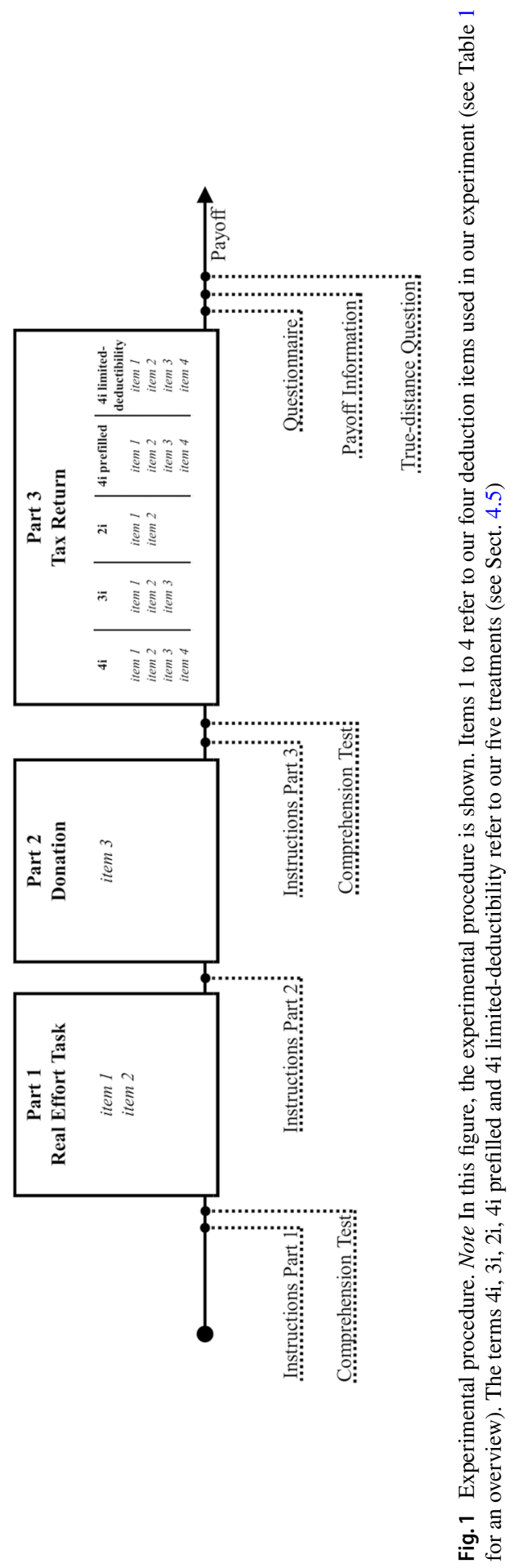


real effort task, $22.6 \%$ of the generated income is withheld as a fictional social insurance contribution (item 1$)^{4}$

Before each round, participants can optionally buy a tool (item 2) that simplifies the real effort task. ${ }^{5}$ More precisely, the amount of numbers is reduced in all matrices of that round (e.g., from twelve to ten). As the amount of irrelevant numbers is reduced, individuals might solve more puzzles within the given time. The tools cost 37 Eurocent (142 Eurocent, 299 Eurocent) and they reduce the amount of numbers from twelve to eleven (ten, nine), respectively. A simplification tool is valid for one round. Before each round, each participant decides whether she wants to buy one of the three simplification tools. ${ }^{6}$

After each round, the number of correctly solved math puzzles, the amount of withhold social insurance contribution, the expenditures for simplification tools and the resulting earned income in that round are displayed to the participants. To complete the tax return in the third part of the experiment, participants are requested to record the displayed information after each round on a piece of paper at their workstation. Piece of paper and pen are provided to the participants.

In the second part of the experiment (donation), participants can optionally donate part of their generated income to real life institutions (item 3). For this purpose, participants can enter an amount of money which they want to donate. They are asked to select institutions out of a list (e.g., UNICEF and Greenpeace). Again, participants are requested to record the donation amount on a piece of paper at their workstation as a preparation for their tax return.

In the third part (tax return), participants have to file a tax return by reporting their deduction items. Participants are also asked to claim a commuting allowance. They do so by entering the distance between their home and the laboratory in kilometers. ${ }^{7}$ For every entered kilometer, participant's taxable income is reduced by 30 Eurocents (commuting allowance, item 4). The most important characteristic of item 4 is the fact that any misreporting is undetectable as the experimenter does not know the true distance. Consequently, this item mirrors expenditures that can only very hardly be verified by the tax authority. ${ }^{8}$ Table 1 highlights the item characteristics.

The taxable income, that is income minus declared deductions for items 1, 2, 3 and 4 , is subject to a tax rate of $40 \%$. The declared income is already prefilled in the tax return and cannot be manipulated by the participants. However, participants have the opportunity to evade taxes if they declare higher deductions than their

\footnotetext{
4 To keep the experiment as simple as possible, participants receive no benefits from social insurance in our experiment.

5 This item mirrors work-related or professional expenditures that might enhance someone's productivity like purchasing a new notebook or attending an advanced training course. Taxable income is usually calculated by subtracting expenditures from earnings (e.g., labor income). This tool and the corresponding expenditures represent a common example for work-related expenditures of employees.

6 In our experiment, we observed that over all five treatments $57.1 \%$ of the participants bought a simplification tool at least during one round.

7 To enter the distance, participants are allowed to use their smartphones and apps like Google Maps.

${ }^{8}$ In real life, tax authorities can check the plausibility of the entered distance quite easily, but are usually unable to retrace how often the taxpayer has traveled the distance in the taxable period.
} 
Table 1 Item overview

\begin{tabular}{|c|c|}
\hline Item & Description \\
\hline Item 1 (social insurance contribution) & $\begin{array}{l}\text { Fixed percentage rate }(22.6 \%) \text { of income. Participants can deduct } \\
\text { the social insurance contribution from their tax base in the tax } \\
\text { return }\end{array}$ \\
\hline Item 2 (work-related expenditures) & $\begin{array}{l}\text { Expenditure that occurs when participants buy tools to simplify } \\
\text { the income generation. Participants can buy these tools for } \\
\text { fixed prices before each of the four rounds of the real effort } \\
\text { task. Participants can deduct the total costs of purchased tools } \\
\text { in the tax return }\end{array}$ \\
\hline Item 3 (donation) & $\begin{array}{l}\text { Expenditure that occurs when participants donate part of their } \\
\text { generated income to real life institutions (e.g. UNICEF, Green- } \\
\text { peace). In the tax return, participants can deduct their donation }\end{array}$ \\
\hline Item 4 (commuting allowance) & $\begin{array}{l}\text { Expenditure that captures participant's costs to arrive at the labo- } \\
\text { ratory. Participants are asked to enter the distance from their } \\
\text { home to the laboratory. For every entered kilometer, partici- } \\
\text { pant's taxable income decreases by } 0.30 €\end{array}$ \\
\hline
\end{tabular}

true expenditures. In the instructions, participants are explicitly asked to declare their true expenditures. Thus, if participants declare higher deductions they engage in tax evasion. Unintentional tax evasion by the taxpayer is virtually excluded by design (our setting is quite simple) and participants are fully aware of their true expenditures. $^{9}$

There is a probability of $30 \%$ that a participant will be audited after she has submitted her tax return. If a participant is audited and her declared taxable income is lower than her true taxable income, she has to pay a fine that is twice the amount of the evaded taxes. This implies that in case of a detected tax evasion, the subject has to repay the evaded taxes plus additional penalty costs of $100 \%$ of the evaded taxes. ${ }^{10}$

After completion of an ex-post questionnaire (see Sect. 4.3), subjects are informed about the audit outcome and their payoff. There is one last question at the very end of the experiment ("true-distance question", details below in Sect. 4.4) before participants privately receive their payoff in cash. The payoff consists of a show-up fee of 4 Euro, a reward for correctly answered comprehension tests (see Sect. 4.2) and the money earned in the experiment (=pre-tax income minus true expenditures minus tax liability minus potential fine).

\footnotetext{
${ }^{9}$ To complete the tax return, participants are asked to use the records they made on the piece of paper. Moreover, participants can press a button on the tax return screen to have their actual expenditures displayed to exclude that record errors bias their compliance behavior. In our experiment, we observed that over all five treatments $40.3 \%$ of the participants pressed the button at least once.

${ }^{10}$ If an audit reveals that the declared taxable income is higher than the true taxable income, the participant gets back the overpaid taxes and no additional costs occur.
} 


\subsection{Comprehension tests}

Prior to part one and also before part three of the experiment, subjects have to complete a monetary incentivized comprehension test. They are asked several questions regarding the puzzle task, pre-tax income determination, tax liability determination, audit probability and payoff determination. If participants answer the questions correctly on their first (second) try, they receive an additional payment of 1 Euro (0.50 Euro), otherwise 0 Euro. The full set of questions is provided in the online Appendix A2.

\subsection{Ex-post questionnaire}

The tax compliance literature provides evidence that several socio-demographic and attitudinal variables have an influence on tax compliance behavior, such as age (Muehlbacher et al. 2011), gender (Kastlunger et al. 2010), risk attitude (Dulleck et al. 2016; Fochmann and Wolf 2019), tax morale (Alm 2019; Kirchler 2007; Lewis 1982; Torgler 2002), income (Grundmann and Graf Lambsdorff 2017; Gangl and Torgler 2020) and emotions (Erard and Feinstein 1994; Bosco and Mittone 1997; Dulleck et al. 2016; Blaufus et al. 2017; Enachescu et al. 2019). At the end of the experiment (but before participants learn their final payoffs, see Fig. 1), participants are therefore asked to answer a questionnaire that collects socio-demographic and attitudinal data. Table 2 provides an overview of relevant variables and the online Appendix A3 contains additional information on the ex-post questionnaire. The answers to these questions are used as controls in our regression analyses.

\subsection{True-distance question}

After the questionnaire and after participants are informed about the audit outcome and their final payoffs, we display a final question to the participants and ask them to enter the true distance from their home to the laboratory. We explicitly point out to the participants that their answer to this question will not affect their final payoff and that the actual experiment is already completed. ${ }^{11}$ This last question enables us to estimate the tax evasion level with item 4 ex-post of the experiment. ${ }^{12}$ However, this analysis has to be treated with caution, because it demands the honesty of the participants. Nevertheless, we feel confident that most participants entered the true value, because of our appeal to be honest and because the participants knew that the actual experiment was over. Furthermore, we observe significant lower and more realistic answers than reported in the tax return of the experiment. ${ }^{13}$

\footnotetext{
11 After the clarification, we literally asked the following question: "In this experiment you were asked to enter the distance from your home to the laboratory and it was up to you to enter a smaller or greater distance. For the analysis of this study we kindly ask you to enter the true distance in kilometers. Again, you are allowed to use your smartphone."

12 There is technically no other way to obtain this information due to the anonymity of our participants.

13 Furthermore, considering this "limitation" makes our following results even stronger. If we assume that some participants still report more than the true number of kilometers we underestimate tax evasion in item 4. Consequently, tax evasion in item 4 might be even higher and our already highly significant results even stronger.
} 


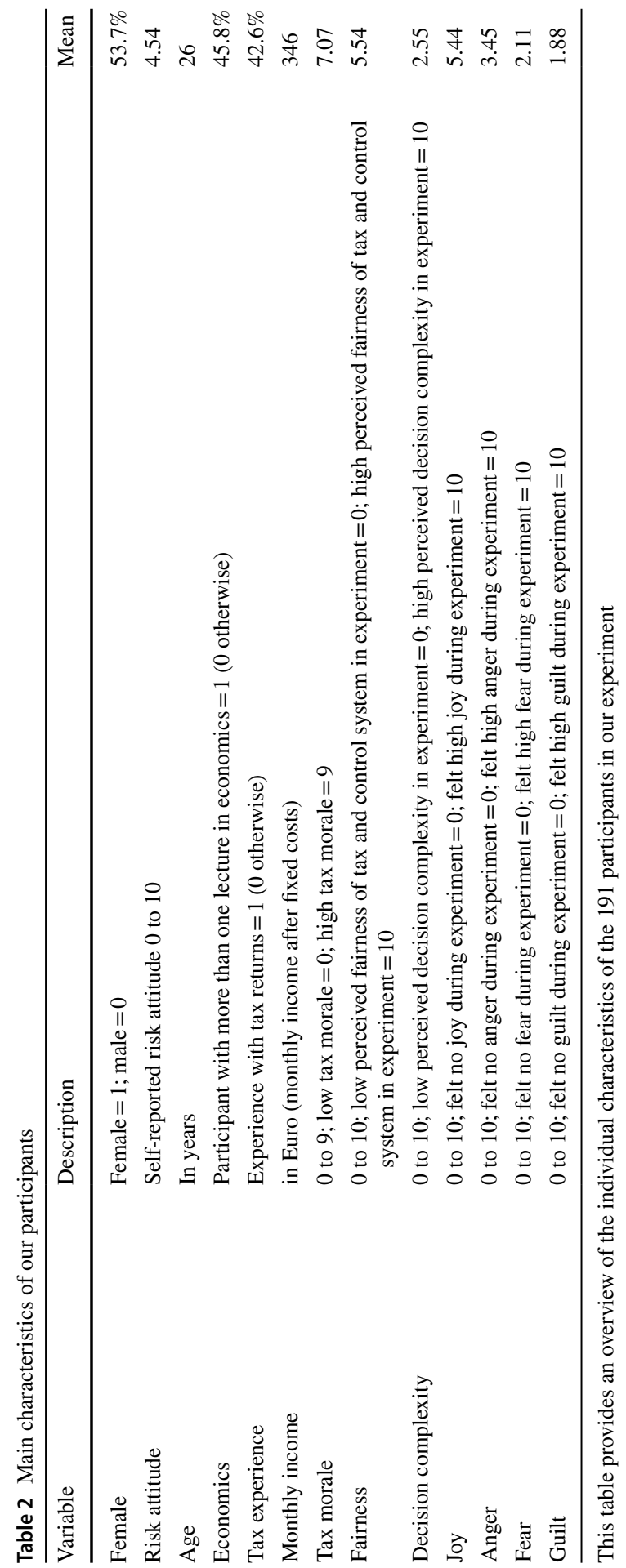



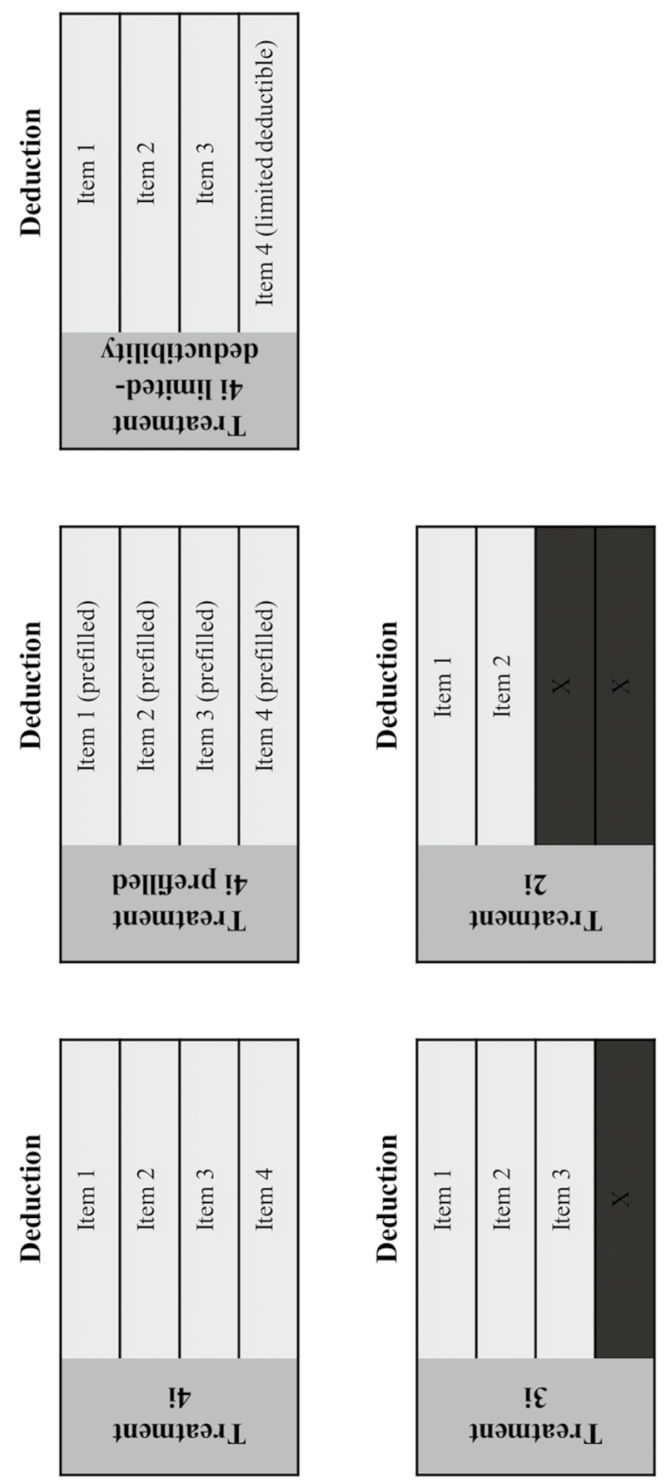

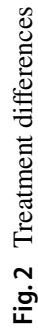




\subsection{Treatments}

Our experiment consists of five treatments (between-subject design). Figure 2 highlights the differences between them. The first treatment allows the deduction of all 4 items in the tax return (base case).

- Treatment $4 i$ (base case) All 4 items are deductible in the tax return.

In the second treatment we prefill each expenditure item with its correct value in the tax return. For item 4 (commuting allowance) we used the median distance reported in the true-distance question in treatment $4 \mathrm{i}$ as the prefilled value for item 4 (that is $5 \mathrm{~km}$ ). ${ }^{14}$ All monetary aspects such as tax rate, audit probability, and penalties are kept constant by this treatment variation. Thus, we exclude that prefilling changes tax compliance behavior through a change in the audit probability or penalty.

- Treatment $4 i$ prefilled All 4 expenditure items are deductible and the deductions are prefilled in the tax return.

In the next two treatments we disallowed the deduction of specific expenditures:

- Treatment $3 i$ (3 items) Items 1, 2 and 3 are deductible in the tax return. Item 4 (commuting allowance) is non-deductible.

- Treatment $2 i$ (2 items) Items 1 and 2 are deductible in the tax return. Items 3 (donation) and 4 (commuting allowance) are non-deductible.

The remaining treatment matches the first treatment (base case) with one exemption regarding item 4 (commuting allowance). Participants are only allowed to deduct a limited amount of 10 Eurocent per kilometer (instead of 30 Eurocent as in the base case). ${ }^{15}$

- Treatment $4 i$ limited-deductibility All 4 expenditure items are deductible. However, participants are only allowed to deduct a limited amount of 10 Eurocent per kilometer in item 4.

We control for all other factors that might influence tax compliance, such as fine and tax rate, by keeping them constant between the different treatments. Also the experimental setting of part one and part two remains constant over all treatments to ensure that any observed difference in compliance behavior is due to the treatment manipulations regarding the tax return in part three of the experiment. This implies,

\footnotetext{
14 Consequently, we conducted treatment $4 \mathrm{i}$ prefilled with a certain time-delay after treatment $4 \mathrm{i}$.

15 Participants in this treatment do not know that the commuting allowance is higher in other treatments. In the instructions in this treatment, we only state that the commuting allowance is 10 Eurocent per kilometer (see online appendix A1.4).
} 


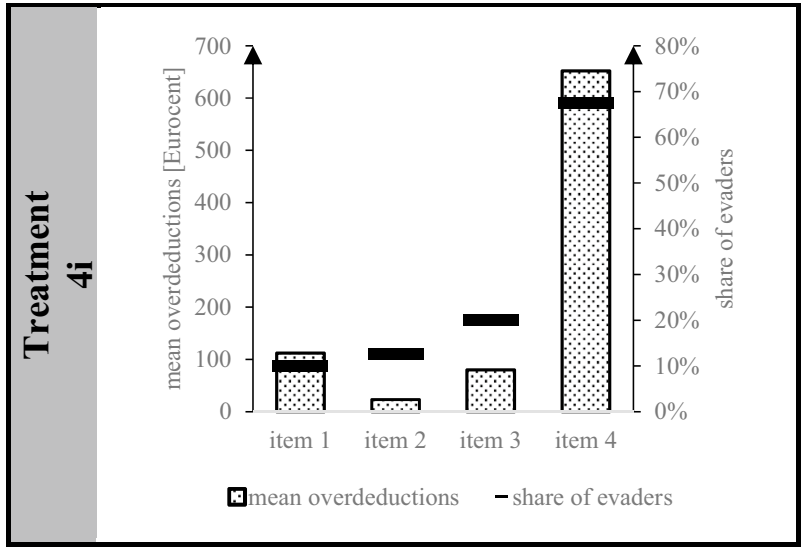

Fig. 3 Tax evasion in treatment $4 \mathrm{i}$

for example, that in treatment $2 \mathrm{i}$ participants still have the opportunity to donate in part two, but that the donation cannot be deducted in part three.

\subsection{Sample and data}

The experiment was conducted at the computerized experimental laboratory of the University of Cologne (CLER) from September to December 2018. The experiment was programmed and executed with the software z-Tree (Fischbacher 2007). Participants were recruited with ORSEE (Greiner 2015). In total, 191 subjects (mainly undergraduate students) participated and earned, on average, 22.11 Euro in approximately $90 \mathrm{~min}$ (approximately 14.74 Euro per hour). A total of 40 subjects were randomly assigned to treatment $4 \mathrm{i}, 42$ to treatment $3 \mathrm{i}, 35$ to treatment $2 \mathrm{i}, 39$ to treatment $4 \mathrm{i}$ prefilled and 35 to treatment $4 \mathrm{i}$ limited-deductibility. Table 2 provides an overview on the main characteristics of the participants collected in our ex-post questionnaire (see Sect. 4.3).

\section{Results}

We use two tax evasion measures to analyze our experimental data. First, we use the interval variable overdeductions which measures the absolute level of overdeductions (i.e., declared deductions minus true deductions). Second, we use the dummy variable evader which takes the value of 1 if a participant evaded any tax (i.e., was not fully compliant). Whereas the variable evader measures whether a participant is fully compliant or not, the variable overdeductions also measures the level of noncompliance (i.e., the magnitude of tax evasion). Both variables overdeductions and 


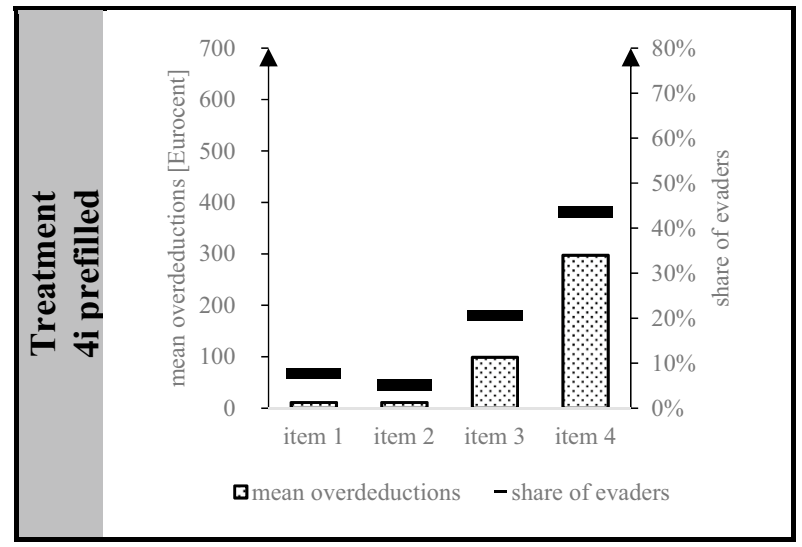

Fig. 4 Tax evasion in treatment $4 \mathrm{i}$ prefilled

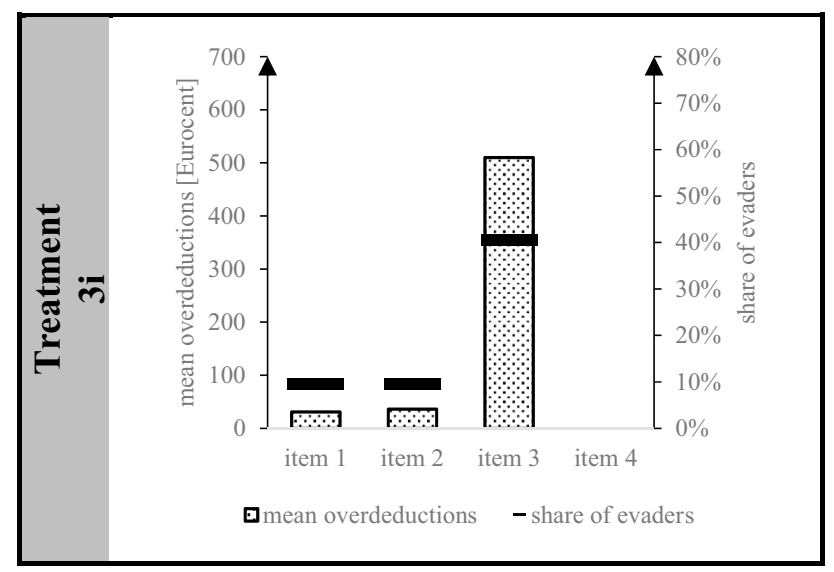

Fig. 5 Tax evasion in treatment $3 \mathrm{i}$

evader are calculated for each item separately. ${ }^{16}$ Figures 3, 4, 5, 6 and 7 show the results of the five treatments which we discuss in the following in more detail.

\subsection{Tax evasion within each treatment}

We start the presentation of our results by analyzing the item-specific tax evasion levels within each treatment. We test for differences between the items by using the McNemar test for variable evader and the Wilcoxon signed-rank test for variable overdeductions (always two-tailed). We robustly observe that item 4 (commuting

$\overline{16}$ In the rare case of underdeductions, both variables are set to 0. 


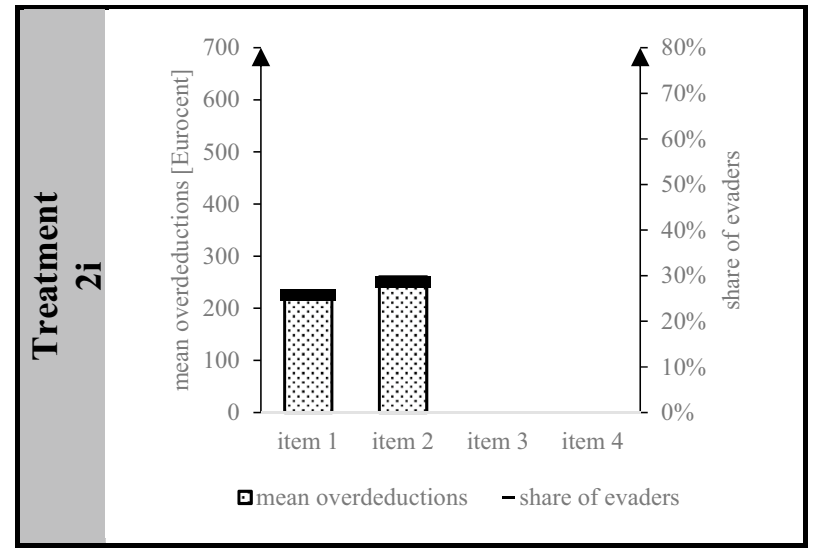

Fig. 6 Tax evasion in treatment $2 \mathrm{i}$

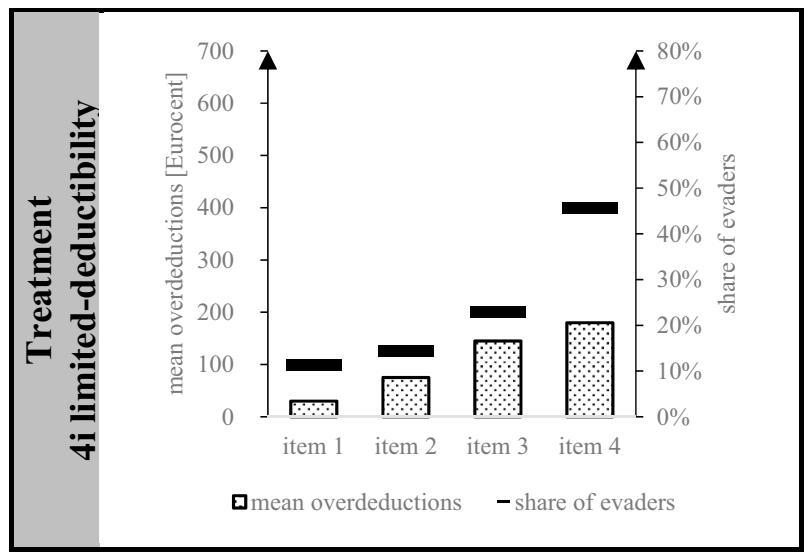

Fig. 7 Tax evasion in treatment $4 \mathrm{i}$ limited-deductibility

allowance) is preferably used for tax evasion - both in terms of share of evaders and overdeductions. As tax evasion cannot be detected with this item in our experiment, this finding is in line with the tax compliance literature. In particular, this literature provides robust evidence that a lower audit/detection probability increases tax evasion (Allingham and Sandmo 1972; Spicer and Thomas 1982; Alm et al. 1995; Maciejovsky et al. 2001; Torgler 2003; Cummings et al. 2009; Fortin et al. 2007; Gërxhani and Schram 2006).

Treatment $4 i$ (base case) Figure 3 shows that the tax evasion level is higher for item 4 than for the other items in treatment 4 i. In particular, $67.5 \%$ of the participants evade taxes with item 4 compared to approx. 10 to $20 \%$ with items 1, 2 and 3 . Mean overdeductions are 112 Eurocent for item 1, 23 for item 2, 80 for item 3 and 652 for 
item 4. All differences between item 4 and the other items are highly significant (all p-values below 0.001). Between items 1, 2 and 3 differences are insignificant (all p-values above 0.1 ).

Treatment $3 i$ Figure 5 shows that $40.5 \%$ of participants evade taxes with item 3 compared to $9.5 \%$ with items 1 and 2 in treatment 3i. Mean overdeductions yield 510 Eurocent for item 3, 36 for item 2 and 31 for item 1. All differences between item 3 and the other two items are highly significant (all p-values below 0.001). No significant differences are observed between items 1 and 2 (all p-values above 0.1 ).

Treatment $2 i$ Figure 6 reveals that $28.6 \%$ of participants evade taxes with item 2 compared to $25.7 \%$ with item 1 in treatment $2 \mathrm{i}$. Mean overdeductions yield 260 Eurocent for item 2 and 221 for item 1. Differences between item 1 and 2 are insignificant (all $p$-values above 0.1 ).

Treatment 4 i prefilled Fig. 4 shows that $43.6 \%$ of participants evade taxes with item 4 compared to $20.5 \%$ with item $3,5.1 \%$ with item 2 and $7.7 \%$ with item 1 in treatment 4i prefilled. Mean overdeductions yield 297 Eurocent for item 4, 99 for item 3 and 11 for item 2 and 1 . All differences between item 4 and the other three items are significant (all $p$-values below 0.05). However, our statistical tests also reveal significant differences between items 1 and 3 for overdeductions $(p=0.0326)$ and significant differences between items 2 and 3 for overdeductions $(p=0.0171)$ and evaders $(p=0.0313)$. For all other item combinations, we find no significant differences (all $p$-values above 0.1 ).

Treatment $4 i$ limited-deductibility Fig. 7 exhibits that $45.7 \%$ of participants evade taxes with item 4 compared to $22.9 \%$ with item 3, $14.3 \%$ with item 2 and $11.4 \%$ with item 1 in treatment $4 \mathrm{i}$ limited-deductibility. Mean overdeductions yield 180 Eurocent for item 4, 145 for item 3, 75 for item 2 and 30 for item 1. All differences between item 4 and the other three items are significant (all $p$-values below 0.05). The only exemption occurs for the comparison between items 4 and 3 where we find no significant difference for the variable overdeductions $(p=0.1994)$. No significant differences are observed between items 1,2 and 3 (all $p$-values above 0.1 ).

\subsection{Prefilling}

To analyze the effect of prefilled tax returns on tax compliance, we compare treatment $4 \mathrm{i}$ with treatment $4 \mathrm{i}$ prefilled (see Figs. 3 and 4). Whereas item 4 is commonly used by the participants for tax evasion in treatment $4 \mathrm{i}$, we find a strong decrease of tax evasion with this item in treatment $4 \mathrm{i}$ prefilled. In particular, overdeductions of item 4 decrease from 652 to 297 and share of evaders from 67.5 to $43.6 \%$. For items 1 and 2, we also observe that prefilling reduces tax evasion, but to a lower extend. Item 3 is unaffected. We explain the small effects for items 1 to 3 by the already low tax evasion levels for these items in treatment $4 \mathrm{i}$. 


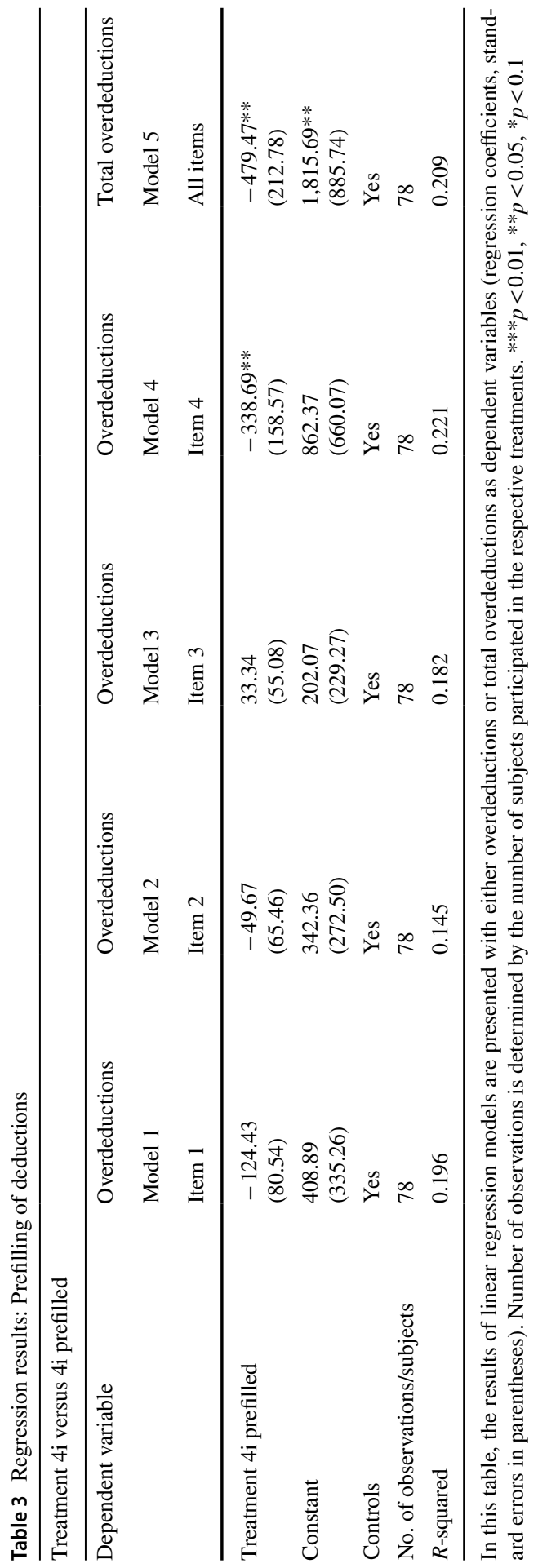


A low tax evasion benchmark might be less-than-ideal to test the effectiveness of prefilling. For example, we observe a decrease in overdeductions from 112 to 11 Eurocent for item 1. This decrease for item 1 is in absolute terms lower than the decrease for item 4. However, overdeductions are getting close to zero (i.e., indicating no tax evasion) with prefilled tax returns and in relative terms the decrease for item 1 (approx. 90\%) is even higher than for item 4 (approx. 54\%). The level of total overdeductions (i.e., sum of overdeductions over all available deduction items) decreases from 867 Eurocent in treatment $4 \mathrm{i}$ to 418 in treatment $4 \mathrm{i}$ prefilled.

The results are also supported by linear regressions (see Table 3 ) with overdeductions (models 1-4) and total overdeductions (sum of overdeductions, model 5) as dependent variables. In all models, we regress on a dummy variable treatment $4 \mathrm{i}$ prefilled that equals 1 if the decision was made in this treatment ( 0 otherwise). Treatment $4 \mathrm{i}$ serves as the default. Moreover, we consider a vector of individual characteristics as controls collected in our ex-post questionnaire (see Sect. 4.3 and Table 2 for details). Controls are not reported in Table 3, but the full set of regression results can be found in our online Appendix A4.1.

We find significantly lower overdeductions for item 4 (model 4), but not for the other items (models 1 to 3), and a significantly lower level of total overdeductions (model 5) in treatment $4 \mathrm{i}$ prefilled than in treatment $4 \mathrm{i}$. The coefficient of the variable treatment $4 \mathrm{i}$ prefilled in model 4 points to (on average) lower overdeductions by 339 Eurocent for item 4 in this treatment compared to treatment $4 \mathrm{i}$. Consequently, our findings support Hypothesis 1 and provide evidence that prefilling is an effective mechanism to reduce tax evasion. We rerun models 1 to 4 also with the item-specific variable evader as dependent variable (logistic regression). All results are robust to this variation. Regression results are provided in the online appendix A4.2.

Result 1 Prefilling deductions in the tax return reduces tax evasion.

\subsection{Disallowing the deductibility of expenditures: Evasion-shift-effect}

We now analyze the effectiveness of deduction-disallowance of specific expenditure items that are commonly used by the participants for tax evasion. For this purpose, we compare the tax evasion levels between treatments 4i, $3 i$ (item 4 not deductible) and $2 \mathrm{i}$ (items 3 and 4 not deductible). See Figs. 3, 5 and 6 for the respective results.

First, a direct comparison of treatment $4 \mathrm{i}$ with treatment $3 \mathrm{i}$ reveals that the level of tax evasion in item 3 increases. In particular, the disallowance to deduct item 4 leads to an increase in overdeductions (share of evaders) in item 3 from 80 Eurocents $(20.0 \%)$ in treatment $4 \mathrm{i}$ to $510(40.5 \%)$ in treatment $3 \mathrm{i}$. Second, a direct comparison of treatment $3 \mathrm{i}$ with treatment $2 \mathrm{i}$ reveals that the level of tax evasion in items 1 and 2 increases. In particular, the disallowance to deduct item 3 leads to an increase in overdeductions (share of evaders) in item 1 from 31 Eurocents $(9.5 \%)$ in treatment $3 \mathrm{i}$ to $221(25.7 \%)$ in treatment $2 \mathrm{i}$ and an increase in overdeductions (share of evaders) in item 2 from 36 Eurocents $(9.5 \%)$ in treatment 3i to $260(28.6 \%)$ in treatment $2 \mathrm{i}$. 


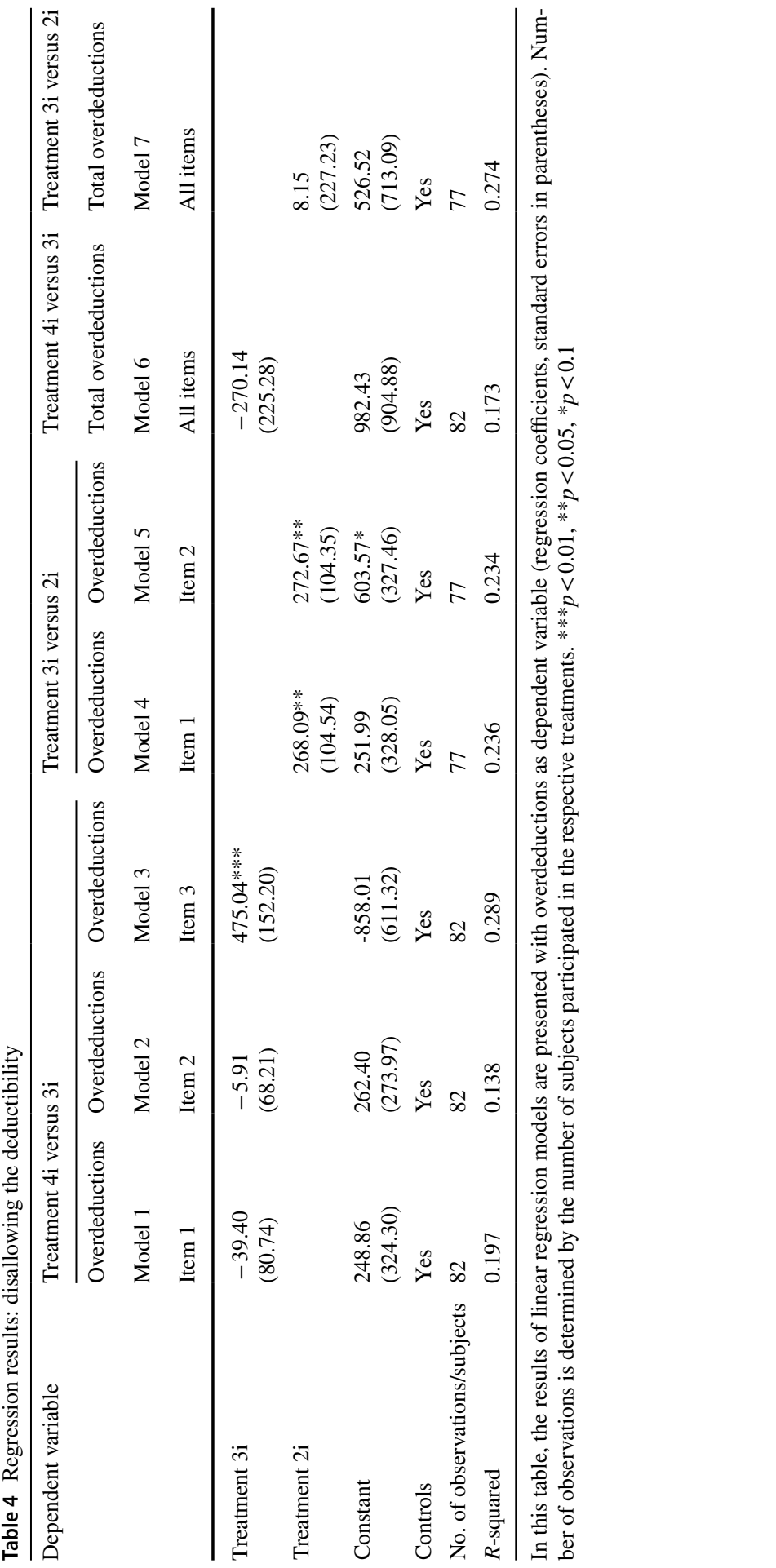


Again, we run linear regressions. The results are presented in Table 4. As dependent variables we again consider overdeductions (models 1-5) or total overdeductions (sum of overdeductions, models 6-7). The variables of interest are dummy variables for the treatments $3 \mathrm{i}$ and $2 \mathrm{i}$. Each treatment variable takes the value of 1 if the decision was made in the respective treatment ( 0 otherwise). In models 1 to 3 and 6 (4, 5 and 7), we consider the dummy variable for treatment $3 \mathrm{i}(2 \mathrm{i})$ and set treatment $4 \mathrm{i}$ (3i) as the default. Again, we consider individual characteristics as controls. ${ }^{17}$

Our results show that disallowing the deductibility of one item affects the tax evasion level of the remaining items. In particular, tax evasion level of item 3 is significantly higher in treatment $3 \mathrm{i}$ - where item 4 is non-deductible - than in treatment $4 \mathrm{i}$ (model 3). However, for items 1 and 2 we do not observe significant differences between both treatments (models 1 and 2). Comparing treatments $3 \mathrm{i}$ and $2 \mathrm{i}$, we find that the tax evasion levels of item 1 (model 4) and of item 2 (model 5) are significantly higher in treatment $2 \mathrm{i}$. In both regression models with total overdeductions as dependent variable (models 6 and 7), we fail to find a significant treatment effect. ${ }^{18}$ Consequently, disallowing the deductibility of expenditures for one item fails to reduce the overall tax evasion level significantly.

In conclusion, we observe an evasion-shift-effect resulting in an increase of tax evasion for at least one of the remaining items. This supports Hypothesis $2 b$ and rejects Hypothesis $2 \mathrm{a}$. This increase is high enough that the level of total overdeductions is not changed significantly.

Result 2 Disallowing the deductibility of expenditures causes an evasion-shifteffect. Individuals shift overdeductions from the restricted item to other nonrestricted items. Overall tax evasion level does not change significantly.

\subsection{Limiting the deductibility of expenditures: no evasion-shift-effect}

Finally, we analyze the effectiveness of limiting the deductibility of an expenditure item. For this purpose, we compare the tax evasion levels between treatment $4 \mathrm{i}$ and treatment $4 \mathrm{i}$ limited-deductibility (see Figs. 3 and 7). For item 4, we observe that overdeductions decrease from 652 to 180 Eurocent. The share of evaders decreases from $67.5 \%$ to $45.7 \%$. For the other items, we fail to find any significant differences between the two treatments. Overall tax evasion (i.e., sum of overdeductions) decreases from 867 Eurocent in treatment $4 \mathrm{i}$ to 430 in treatment $4 \mathrm{i}$ limited-deductibility.

\footnotetext{
17 Please notice that we rerun models 1 to 5 also with the item-specific variable evader as dependent variable (logistic regression). All results are robust to this variation and regression results are provided in the online appendix A4.3.

18 The 95\% confidence interval for the coefficient of the dummy variable Treatment $3 \mathrm{i}$ (model 6) ranges from.

-719.8 to 179.5 and for the coefficient of the dummy variable Treatment $2 \mathrm{i}$ (model 7) from -446.1 to 462.4. Both coefficients measure the mean change in total overdeductions in case of disallowing the deductibility of an expenditure item.
} 


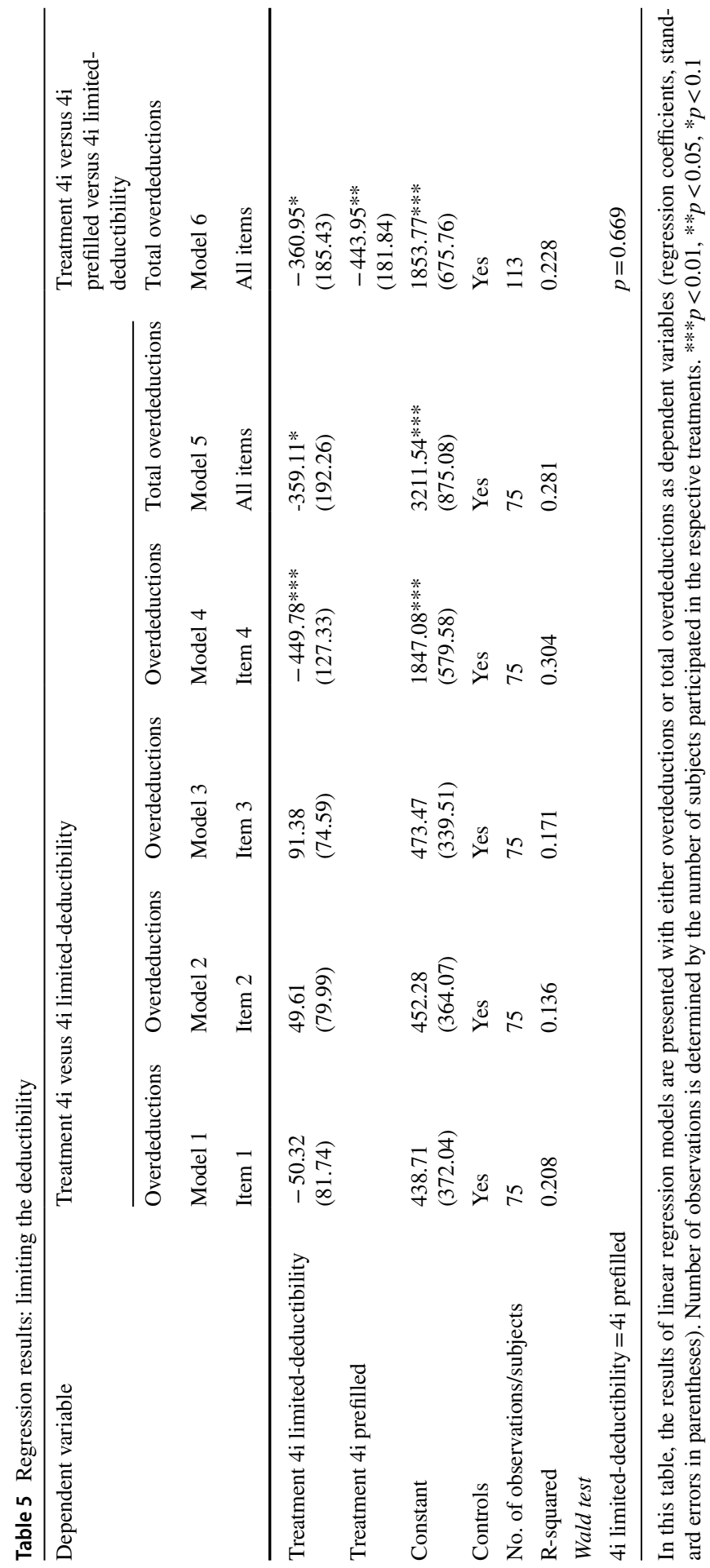


These findings are supported by linear regressions (see Table 5) with overdeductions (models 1-4) and total overdeductions (models 5-6) as dependent variables. In all models, we regress on a dummy variable treatment limited-deductibility that equals 1 if the decision was made in this treatment ( 0 otherwise). Treatment $4 \mathrm{i}$ serves as the default. Moreover, we consider individual characteristics as controls. ${ }^{19}$ We find significantly lower overdeductions for item 4 (model 4), but not for the other items (models 1 to 3), and a significantly lower level of total overdeductions (models 5 and 6 ) in treatment $4 \mathrm{i}$ limited-deductibility than in treatment $4 \mathrm{i}^{20}$ Consequently, we provide evidence that there is no evasion-shift-effect in treatment $4 \mathrm{i}$ limiteddeductibility. In particular, a limited deductibility for one item does not affect the tax evasion level of the other items. Consequently, a limited deductibility seems to be an effective mechanism to reduce tax evasion. Our results therefore support Hypothesis $3 \mathrm{a}$ and reject Hypothesis $3 \mathrm{~b}$.

Result 3 Limiting the deductibility of an expenditure causes no evasion-shifteffect. Individuals do not shift overdeductions from the restricted item to other nonrestricted items.

In model 6 , we additionally include the observations from treatment $4 \mathrm{i}$ prefilled to also test for differences between treatment $4 \mathrm{i}$ limited-deductibility and $4 \mathrm{i}$ prefilled. We observe no significant difference between both treatments in overall tax evasion (checked by Wald test). Previous results are supported.

\subsection{Robustness tests}

\subsubsection{Order effects}

In treatments $4 \mathrm{i}$ and $3 \mathrm{i}$ always the last expenditure item (presented in the respective tax return) has the highest level of tax evasion. Although treatment $2 \mathrm{i}$ lacks this observation, we conducted two additional treatments with small sample size to provide some evidence that order effects do not bias the observed behavior. In these robustness treatments, we reversed the order of the presented items in the respective tax return. In all other aspects treatment $4 \mathrm{i}$-inverse-order $(\mathrm{N}=12)$ follows treatment $4 \mathrm{i}$ and treatment $3 \mathrm{i}$-inverse-order $(\mathrm{N}=19)$ follows treatment 3i. Again, tax evasion level is highest for item 4 in treatment $4 \mathrm{i}$-inverse-order and highest for item 3 in treatment 3i-inverse-order. Also in line with our previous results, we observe the lowest tax evasion level for items 1 and 2. Therefore, these findings provide some evidence that order effects do not bias the tax evasion decisions of the participants. Please note that the results of the two robustness treatments must be interpreted with caution due to the low number of observations.

\footnotetext{
${ }^{19}$ Please notice that we rerun models 1 to 4 also with the item-specific variable evader as dependent variable (logistic regression). All results are robust to this variation and regression results can be found in the online appendix A4.4.

${ }^{20}$ The 95\% confidence interval for the coefficient of the dummy variable Treatment $4 \mathrm{i}$ limited-deductibility ranges from -743.7 to 25.5 in model 5 and from -729.0 to 7.1 in model 6 .
} 


\subsubsection{Perceived Audit Probability}

There is ample evidence that an increased audit probability increases tax compliance (see Torgler 2002 and Alm 2019 for an overview). Although our treatment variation has no influence on the objective audit probability to detect tax fraud, it might be that the subjective perception of the audit probability is affected. For example, Kogler et al. (2016) observe that their experimental manipulations changed the subjective audit probability although the objective audit probability, which was explicitly mentioned to their participants before the experiment started, was unchanged. However, we provide evidence that a change in subjective/perceived audit probability can be excluded as an explanation for our observed treatment differences. We asked our participants in our ex-post questionnaire: "How did you perceive the audit probability in the experiment?" (10-point Likert scale from "very low" to "very high"). Over our main five treatments, the mean answer was 3.97. Differences across treatments were small and statistically insignificant (Kruskal-Wallis test, $p=0.679$, two-tailed).

\subsubsection{Button to display the actual expenditures}

As outlined in Sect. 4.1, participants had a button on the tax return screen of the experiment that displayed their actual expenditures (see footnote 4). As a robustness test, we rerun all regressions and included additionally — as a control variable - how often a participant pressed this button. All results are robust to this variation. Moreover, the control variable never shows up significantly in the regressions.

\section{Discussion and conclusion}

We analyzed three anti-tax-evasion mechanisms that focus on deductions: (1) prefilling of deductions in tax returns and (2) restricting tax evasion opportunities by either disallowing or (3) limiting the deductibility of specific expenditures.

Our results suggest that prefilled deductions enhance tax compliance. In particular, item-specific tax evasion level decreases-especially for items preferred for tax evasion-and as a consequence overall tax evasion level is reduced. As we do not observe that the subjective perception of audit probabilities varies significantly across treatments, the positive effect of prefilling might be primarily driven by higher non-monetary costs associated with tax evasion under this mechanism. This finding highlights the importance of non-monetary and psychological factors for the design of tax regulations.

Disallowing the deductibility of one expenditure item (i.e., cutting the number of tax evasion opportunities) is an ineffective mechanism to combat tax evasion. In fact, individuals shift their tax evasion activities from the disallowed item to other non-restricted items (evasion-shift-effect). However, our results suggest that limiting the deductibility (in contrast to disallowing the deductibility completely) avoids this evasion-shift-effect and finally reduces overall tax evasion. Remarkably, disallowing the deductibility of expenditures completely might lead to a reduction in perceived 
procedural fairness. This might explain why we find a shift-effect in the former case, but not in the latter one.

We conclude that policy makers trying to combat tax evasion should-if technically feasible-prefill deductions in tax returns. Whereas our results suggest that a disallowance of deductions results in an evasion-shift-effect, policy makers might avoid this effect by only limiting the deductible amount. ${ }^{21}$ While we observe similar effects of prefilling tax returns and limiting (not disallowing) the deductibility of expenditures on overall tax evasion level, both mechanisms differ in their approach. Whereas limiting the deductibility constrains the monetary benefit of tax evasion directly, prefilling does not change any tax evasion opportunity or the objective monetary costs or benefits of tax evasion. If technically feasible, prefilling might be easier to implement than changing the tax law to limit the deductibility of expenditures. Whereas the former just requires a change in the administrative process (and is already performed by tax preparation software), the latter needs democratic justification. More importantly, disallowing or limiting the deductibility can be characterized as a lump-sum solution that also affects the tax bill of individuals who would comply anyway. Whereas prefilling comes without these negative consequences for honest taxpayers, it influences the compliance behavior and the effective tax bill of individuals who tend to evade taxes by claiming additional expenditures in their tax statements.

Our study does have limitations. One limitation is that our sample primarily consists of students. Although this has several strong advantages (e.g., homogenous sample, high cognitive capability, low opportunity costs to ensure incentive compatibility), our results have to be treated with caution regarding external validity. However, as we are not interested in complex case studies where special expertise is crucial, we decided to use students. Moreover, there is much evidence that student decision-making does not differ significantly from that of professionals and non-students - especially if the complexity of the applied experimental task is low like in our experiment (Alm et al. 2015; Depositario et al. 2009; Remus 1996; Ashton and Kramer 1980; Elliott et al. 2007). Therefore, we feel confident that using students as subjects is appropriate in our setting.

The statistical power of experiments is an important issue in experimental economics and potentially also in our study. Therefore, we were cautious in interpreting our results-especially if we found no statistically significant differences. In this regard, further research addressing specific findings of our study might be useful. For example, prefilling reduces tax evasion for almost all items, but a statistically significant effect is only observed for item 4 which is the item that is mostly used for tax evasion. Future research might help to identify whether prefilling has a general effect or affects primarily items with already high tax evasion levels. Moreover, further research is needed to provide more evidence on how disallowing and limiting the deductibility of expenditures impact the overall tax evasion level. In our study, we did not find a statistically significant reduction in case of a disallowance. In case of limiting the deductibility,

\footnotetext{
${ }^{21}$ For example, expenditures related to taxable earnings (e.g., labor income) are in many cases (at least somehow) related to the private sphere. Here, the legislator decides whether a full, partial or no deduction of such expenditures is applied.
} 
we observe a statistically significant reduction, but only at a $10 \%$ level. Therefore, the results regarding the overall tax evasion level must be interpreted with caution.

Acknowledgements We thank the editor, two anonymous referees, James Alm, Peter N.C. Mohr and Kay Blaufus for helpful comments and suggestions.

Funding Open Access funding enabled and organized by Projekt DEAL.

Open Access This article is licensed under a Creative Commons Attribution 4.0 International License, which permits use, sharing, adaptation, distribution and reproduction in any medium or format, as long as you give appropriate credit to the original author(s) and the source, provide a link to the Creative Commons licence, and indicate if changes were made. The images or other third party material in this article are included in the article's Creative Commons licence, unless indicated otherwise in a credit line to the material. If material is not included in the article's Creative Commons licence and your intended use is not permitted by statutory regulation or exceeds the permitted use, you will need to obtain permission directly from the copyright holder. To view a copy of this licence, visit http://creativecommons.org/licenses/by/4.0/.

\section{References}

Adhikari B, Alm J, Collins B, Sebastiani M, Wilking E (2016) Taxpayer responses to third-party income reporting: evidence from a natural experiment in the taxicab industry, 2016

Agostini CA, Martínez AC (2014) Response of tax credit claims to tax enforcement: evidence from a quasi-experiment in Chile. Fisc Stud 35(1):41-65

Allingham MG, Sandmo A (1972) Income tax evasion: a theoretical analysis. J Public Econ $1(3-4): 323-338$

Alm J (2012) Measuring, explaining, and controlling tax evasion: lessons from theory, experiments, and field studies. Intern Tax Public Finance 19(1):54-77

Alm J (2019) What motivates tax compliance? J Econ Surv 33(2):353-388

Alm J, Bloomquist KM, McKee M (2015) On the external validity of laboratory tax compliance experiments. Econ Inq 53(2):1170-1186

Alm J, Sanchez I, de Juan A (1995) Economic and noneconomic factors in tax compliance. Kyklos 48(1): $1-18$

Andreoni J, Erard B, Feinstein J (1998) Tax compliance. J Econ Lit 36(2):818-860

Asatryan Z, Peichl A (2017) Responses of firms to tax, administrative and accounting rules: evidence from Armenia

Ashton RH, Kramer SS (1980) Students as surrogates in behavioral accounting research: some evidence. J Acc Res 18(1):1-15

Becker GS (1968) Crime and punishment: an economic approach. J Political Econ 76(2):169-217

Blaufus K, Bob J, Otto PE, Wolf N (2017) The effect of tax privacy on tax compliance-an experimental investigation. Eur Acc Rev 26(3):561-580

Bosco L, Mittone L (1997) Tax evasion and moral constraints: some experimental evidence. Kyklos 50(3):297-324

Bruner D, Jones M, McKee M, Vossler C (2015) Tax reporting behavior: underreporting opportunities and prepopulated tax returns: Department of Economics, Appalachian State University

Carrillo P, Pomeranz D, Singhal M (2017) Dodging the taxman. Am Econ J Appl Econ 9(2):144-164

Chapman GB, Johnson EJ (1999) Anchoring, activation, and the construction of values. Organ Behav Hum Decis Process 79(2):115-153

Cummings RG, Martinez-Vazquez J, McKee M, Torgler B (2009) Tax morale affects tax compliance: evidence from surveys and an artefactual field experiment. J Econ Behav Organ 70(3):447-457

Depositario DPT, Nayga R, Wu X, Laude TP (2009) Should students be used as subjects in experimental auctions? Econ Lett 102(2):122-124

Dulleck U, Fooken J, Newton C, Ristl A, Schaffner M, Torgler B (2016) Tax compliance and psychic costs: behavioral experimental evidence using a physiological marker. J Public Econ 134:9-18 
Duncan D, Li D (2018) Liar liar: experimental evidence of the effect of confirmation-reports on dishonesty. South Econ J 84(3):742-770

Elliott WB, Hodge FD, Kennedy JJ, Pronk M (2007) Are MBA students a good proxy for nonprofessional investors? Acc Rev 82(1):139-168

Enachescu J, Olsen J, Kogler C, Zeelenberg M, Breugelmans SM, Kirchler E (2019) The role of emotions in tax compliance behavior: a mixed-methods approach. J Econ Psychol 74:102194

Epley N, Gilovich T (2001) Putting adjustment back in the anchoring and adjustment heuristic: differential processing of self-generated and experimenter-provided anchors. Psychol Sci 12(5):391-396

Erard B, Feinstein J (1994) The role of moral sentiments and audit perceptions in tax compliance: Carleton University, Department of Economics

Evans C, Tran-Nam B (2010) Managing tax system complexity: building bridges through pre-filled tax returns. Aust Tax Forum 2:245-274

Feldstein M (2015) Raising Revenue by Limiting Tax Expenditures. Tax Policy and the Economy 29(1):1-11

Fischbacher U (2007) z-Tree: Zurich toolbox for ready-made economic experiments. Exp Econ 10(2):171-178

Fochmann M, Müller N, Overesch M (2018) Less cheating? The effects of prefilled forms on compliance behavior. Available at SSRN 3206410

Fochmann M, Wolf N (2019) Framing and salience effects in tax evasion decisions-an experiment on underreporting and overdeducting. J Econ Psychol 72:260-277

Fonseca MA, Grimshaw SB (2017) Do behavioral nudges in prepopulated tax forms affect compliance? Experimental evidence with real taxpayers. J Public Policy Mark 36(2):213-226

Fortin B, Lacroix G, Villeval M-C (2007) Tax evasion and social interactions. J Public Econ 91(11):2089-2112

Gangl K, Torgler B (2020) How to achieve tax compliance by the wealthy: a review of the literature and agenda for policy. Soc Issues Policy Rev 14(1):108-151

Gërxhani K, Schram A (2006) Tax evasion and income source: a comparative experimental study. J Econ Psychol 27(3):402-422

Gillitzer C, Skov PE (2018) The use of third-party information reporting for tax deductions: evidence and implications from charitable deductions in Denmark. Oxford Econ Pap 70(3):892-916

Goolsbee A (2006) The simple return: reducing America's tax burden through return-free filing: Brookings Institution

Gordon JPP (1989) Individual morality and reputation costs as deterrents to tax evasion. Eur Econ Rev 33(4):797-805

Greiner B (2015) Subject pool recruitment procedures: organizing experiments with ORSEE. J Econ Sci Assoc 1(1):114-125

Grundmann S, Graf Lambsdorff J (2017) How income and tax rates provoke cheating - an experimental investigation of tax morale. J Econ Psychol 63:27-42

Hofmann E, Hoelzl E, Kirchler E (2008) Preconditions of voluntary tax compliance: knowledge and evaluation of taxation, norms, fairness and motivation to cooperate. J Psychol 216:209-217

Johnson EJ, Goldstein D (2003) Do defaults save lives? Science 302(5649):1338

Kastlunger B, Dressler SG, Kirchler E, Mittone L, Voracek M (2010) Sex differences in tax compliance: differentiating between demographic sex, gender-role orientation, and prenatal masculinization (2D:4D). J Econ Psychol 31(4):542-552

Kim Y (2003) Income distribution and equilibrium multiplicity in a stigma-based model of tax evasion. J Public Econ 87(7):1591-1616

Kirchler E (2007) The economic psychology of tax behaviour. Cambridge University Press, Cambridge

Kirchler E, Hoelzl E, Wahl I (2008) Enforced versus voluntary tax compliance: the "slippery slope" framework. J Econ Psychol 29(2):210-225

Kleven HJ, Knudsen MB, Kreiner CT, Pedersen S, Saez E (2011) Unwilling or unable to cheat? Evidence from a tax audit experiment in Denmark. Econometrica 79(3):651-692

Klun M (2009) Pre-filled income tax returns: reducing compliance costs for personal income taxpayers in Slovenia. Financ Theory Pract 33(2):219-233

Kogler C, Mittone L, Kirchler E (2016) Delayed feedback on tax audits affects compliance and fairness perceptions. J Econ Behav Organ 124:81-87

Kotakorpi K, Laamanen J-P (2016) Prefilled income tax returns and tax compliance: evidence from a natural experiment: University of Tampere, School of Management, Economics

Lewis A (1982) The social psychology of taxation. Br J Soc Psychol 21(2):151-158 
Lowry S (2014) Itemized tax deductions for individuals: data analysis

Maciejovsky B, Kirchler E, Schwarzenberger H (2001) Mental accounting and the impact of tax penalty and audit frequency on the declaration of income: an experimental analysis: Humboldt University of Berlin, Interdisciplinary research project 373: Quantification and simulation of economic processes

Mazar N, Amir O, Ariely D (2008) The dishonesty of honest people: a theory of self-concept maintenance. J Mark Res 45(6):633-644

Mazar N, Hawkins SA (2015) Choice architecture in conflicts of interest: defaults as physical and psychological barriers to (dis)honesty. J Exp Soc Psychol 59:113-117

Muehlbacher S, Kirchler E, Schwarzenberger H (2011) Voluntary versus enforced tax compliance: Empirical evidence for the "slippery slope" framework. Eur J Law Econ 32:89-97

Myles GD, Naylor RA (1996) A model of tax evasion with group conformity and social customs. Eur J Polit Econ 12(1):49-66

OECD (2017) Third-party data management - the journey from post-assessment crosschecking to prefilling and no-return approaches. Tax administration 2017: comparative information on OECD and other advanced and emerging economies. OECD Publishing, Paris

Prinz A, Muehlbacher S, Kirchler E (2014) The slippery slope framework on tax compliance: an attempt to formalization. J Econ Psychol 40:20-34

Remus W (1996) Will behavioral research on managerial decision making generalize to managers? Manag Decis Econ 17(1):93-101

Schizer DM (2015) Limiting tax expenditures. Tax Law Rev 68(2):275-354

Slemrod J (2016) Tax compliance and enforcement: new research and its policy implications. Available at SSRN 2726077

Slemrod J, Collins B, Hoopes JL, Reck D, Sebastiani M (2017) Does credit-card information reporting improve small-business tax compliance? J Public Econ 149:1-19

Smith S (2012) Increasing charitable giving: what can we learn from economics?*. Fisc Stud 33(4):449-466

Spicer MW, Thomas JE (1982) Audit probabilities and the tax evasion decision: an experimental approach. J Econ Psychol 2(3):241-245

Srinivasan TN (1973) Tax evasion: a model. J Public Econ 2(4):339-346

Strack F, Mussweiler T (1997) Explaining the enigmatic anchoring effect: mechanisms of selective accessibility. J Pers Soc Psychol 73(3):437

Torgler B (2002) Speaking to theorists and searching for facts: tax morale and tax compliance in experiments. J Econ Surv 16(5):657-683

Torgler B (2003) Tax morale and institutions. Available at SSRN 663686

Traxler C (2010) Social norms and conditional cooperative taxpayers. Eur J Polit Econ 26(1):89-103

Tversky A, Kahneman D (1974) Judgment under uncertainty: heuristics and biases. Science 185(4157):1124

Vossler CA, Gilpatric SM (2018) Endogenous audits, uncertainty, and taxpayer assistance services: theory and experiments. J Public Econ 165:217-229

Yitzhaki S (1974) Income tax evasion: a theoretical analysis. J Public Econ 3(2):201-202

Publisher's Note Springer Nature remains neutral with regard to jurisdictional claims in published maps and institutional affiliations. 